\title{
Prioritization of Tools in Joint Production-Maintenance Environment of Auto Component Manufacturer Using AHP-Fuzzy-TOPSIS
}

\author{
Sanjay Sharma $^{1} \cdot$ Chandan $^{1} \cdot$ Akshat Sisodia $^{1}$
}

Received: 23 October 2015 / Revised: 28 January 2016 / Accepted: 21 February 2016 / Published online: 5 March 2016

(C) Springer Science+Business Media Singapore 2016

\begin{abstract}
Maintenance of tools is one of the areas of maintenance which has been less explored. While maintenance of machinery has a number of research works to its cause, the same cannot be said for tools. In this paper we have identified the unique maintenance needs of the tools and the challenges it present in case of joint production-maintenance environment especially with regard to efficient allocation of resources. Various methods of maintenance planning are reviewed and their suitability is studied. Due to the resources constraint, prioritization of tools for maintenance becomes important. In this work, we have considered the environment of an auto component manufacturer, where there are a number of tools which needs to be serviced on the basis of time and counter. The approach proposed for prioritization is AHP-Fuzzy-TOPSIS as it provides the best combination of quantitative as well as qualitative parameters. Through the use of this methodology we have presented a final ranking which can be used by management for deciding on the optimum allocation of resources.
\end{abstract}

Keywords Prioritization of tools - Joint productionmaintenance $\cdot$ AHP $\cdot$ Fuzzy $\cdot$ TOPSIS

Sanjay Sharma

s_nsit@ rediffmail.com

1 National Institute of Industrial Engineering (NITIE), Vihar Lake, Mumbai 400087, India

\section{Introduction}

Maintenance can be defined as the activity that restores the performance, safety, reliability, and availability of structures, components and systems to ensure superior performance of their intended function [22]. Maintenance is a parallel activity that keeps the production up and is a health check of machines so that a sudden failure is avoided. Though maintenance involves cost but it saves much more by avoiding unwanted failures. Hence in a way it reduces costs of operation [9]. In UK Manufacturing Industry, maintenance costs are $12-23 \%$ of total operating costs [7]. Preventive maintenance prevents the failure of production plans [19]. With the advent of production philosophies like lean and JIT, the role of maintenance has become more critical. In fact, TPM philosophy sums up the importance of maintenance in achieving the business goals. Resources are a constraint hence it becomes important that their deployment is optimised and this is what we have proposed in this paper.

Traditionally, production plan is considered as a precursor to maintenance plan and maintenance has remained as a support function to production. But with the advent of TPM, TQM and TPS methodology, an integrated approach to manufacturing has gained ground. In such an environment activities are considered as concurrent rather than following a sequence. The move is from chain to network and understanding the linkages among them and how they impact the end result altogether. Maintenance in general has remained a field which is largely stochastic and the approaches have been more concerned about mapping it to more important production function. Maintenance planning depends largely on the availability of equipment and hence a rigid procedure is neither possible nor followed considering the targets of production. As the maintenance undertaken deviates from plan the reliability decreases given by a number of distributions, 
most notably by Weibull. In general maintenance activities are classified as breakdown, preventive and predictive. Though predictive maintenance provides a good measure of when to undertake the maintenance, it involves higher cost and is not applicable in all scenarios. For the environment of tools like dies, surface plates, etc. it is difficult to measure their condition. Predictive maintenance is best suited to equipment where online monitoring can be employed. It is generally used for rotary equipments which are critical, as the cost of conditional monitoring is high. Therefore the preventive maintenance is incorporated in the present paper.

The paper consists of six sections. In "Auto Components Manufacturing and Maintenance Environment" section, overview of manufacturing environment for the auto components is discussed. The section entails the unique features that create hurdles in optimizing the available resources. It also discusses the various conventional maintenance practices that are generally followed along with some of the upcoming techniques such as artificial intelligence. In "Methodology" section, the research methodology is explained with regards to AHP-Fuzzy-TOPSIS. The proposed model along with the algorithm and research data and findings are listed in "Proposed Model" section. Conclusion and future scope are discussed in "Conclusion and Future Scope" section.

\section{Auto Components Manufacturing and Maintenance Environment}

In case of auto components manufacturing environment, the production plan is dependent on the companies the firm is supplying. Generally the forecast for the coming month is provided at the end of current month. Hence the production plan is not known very well in advance and it becomes difficult to have a long term maintenance plan even if the management is serious about it. Mostly the companies carry extra tools so that in case of breakdown they can be replaced easily while the maintenance is on the basis of availability. In such an environment two things happen, (1) there is less visibility about the reliability of the tool (2) the manpower allocation is suboptimal. Consider a case where there is high demand of a particular component, in such cases there is little chance for tool to be available for maintenance and the reliability will gradually decrease. So the predictability of failure reduces and uncertainty increases. On the other hand, due to such a schedule optimization of resource allocation becomes difficult. During times of high production demand, the maintenance department is overstaffed, as they do not have tools to work upon. If maintenance is announced for a short time, which happens during peak demand periods, there is a chaos everywhere and the department with the same number of staff may be understaffed. Also during periods of low demand the departments are overstaffed. This fact is neglected in most of the studies and resource levelling for maintenance activities is a considerable cost centre specially in case of specialised maintenance.

Taking further the importance of this paper is the fact that most of the literature available has considered machines for maintenance scheduling and optimization while little attention has been given to maintenance of tools. In this paper our focus is on tools where the problem is magnified because of sheer number and difficulty in predicting their useful life. In the paper we have focussed specifically on prioritization of tools for maintenance for auto components manufacturer which supplies to a number of OEMs. The fact that it supplies to a number of OEMs further increases the number of tools required to produce the same part for different OEMs with different specifications, making tools exclusive. Before moving to the methodology, a quick insight into the field of study might be helpful in understanding the underlying complexities.

Auto component manufacturers generally supply to a large number of OEMs similar kinds of parts but with customised specifications. Hence though the machines on which the operations are carried out are same but the tools required that give final dimension to the product are different. For example, roller heads used for visco-clutch are different for different models though it is mounted on the same rolling machine. Hence every time a new component is to be made for different model, setup is required. Hence the number of tools like these is large. Preparing preventive maintenance plan for such an environment is complex with large number of variables to be considered. The scenario gets further complicated as OEMs communicate component requirement only a month before. In general the maintenance is planned on the basis of:

- Time based In case of time based, maintenance activity is carried out after a pre-specified time irrespective of the production rate or condition of the tool. Though if it is found that the tool is sufficiently "good as new" the activity can be postponed but still the schedule is there. Generally less critical tools are subjected to such schedule.

- Counter based In case of counter based, maintenance activity is carried out when the counter reaches a preset value and hence it is dependent on the production rate and cannot be specified when it will exactly happen. This is for important tools and whose reliability is highly correlated with the production rates.

- Time plus counter based In such case whichever, i.e., time or counter first reaches the pre-set value, maintenance is done at that point. This is employed for the most critical of the tools where the uncertainty of failure is high and high costs are associated with their failure. 
In case of time based preventive maintenance, resource levelling can be smooth but in case of counter based it becomes a crunchy affair. Maintenance involves cost and this cost needs to be minimized. Preventive maintenance takes care of this by reducing the breakdowns and thus avoiding costly repairs and downtimes. The task now at hand is optimizing the maintenance schedule so as to minimize the cost of preventive maintenance. Mostly the organizations have fixed number of maintenance manpower. The question then is how to decide manpower and how to maximise their productivity.

Time based maintenance schedule can help in realising the number of maintenance hours required, so accordingly the manpower can be determined by taking into consideration any additional requirements. In case of time based, subsequent maintenance can be planned keeping in mind the number available thus not overshooting the available manpower. Counter based method provides some difficulty in this regard as it is dependent on production rate. Generally, the products are manufactured on flow lines, hence if a product is manufactured it would go through all the machines/tools in that flow line incrementing the counter by one. Experience shows that such an arrangement reaches the pre-specified values in clusters, i.e. a large number of tools will be required to be serviced at same point in time and at other times the number might be significantly low. This presents trouble in resource allocation as during clustered periods the demand for manpower rises while during other periods it remains low. Hence optimum allocation of manpower is difficult to achieve. This calls for generation of joint production-maintenance planning to reduce interference in production schedule for maintenance activities while avoiding any breakdown.

Other than the traditional maintenance techniques, artificial intelligence (AI) is being adapted in this field. Gopalakrishnan et al. [10] proposed a heuristic based on tabu search for scheduling preventive maintenance.

Few of the techniques used are:

- Neural network

- Fuzzy logic

- Expert systems

- Model based systems

Chen et al. [3] proposed a web-enabled intelligent maintenance optimization programme within limited maintenance resources. Others have used genetic algorithms [17], evolutionary algorithms [15] and neural nets [6] for same purposes. Few researchers have also proposed reliability centred maintenance (RCM) using FMEA and proposing actions on the basis of RPN number [13].

Tsang [20] argues that experience with equipment, knowledge based judgement and recommendation from vendor are required to decide the content and frequency of maintenance.
The conversion of this data into quantitative values on the basis of which some action can be taken is a tough task. Here fuzzy is helpful in converting these linguistic variables into a model that can be used to prioritize the importance of the equipment for maintenance activities. This is particularly useful in the study we have undertaken as obtaining reliable and sufficient data is difficult for the parameters therefore subjective evaluation is needed thus making a good case for use of fuzzy in this scenario.

TOPSIS is used for the following reasons:

- TOPSIS logic is rational and understandable

- The computational processes are straightforward

- The concept permits the pursuit of best alternatives for each criterion depicted in a simple mathematical form

- The importance weights are incorporated into the comparison procedures [21]

In this paper we present a framework for identifying the importance of various tools and prioritizing them for consideration in maintenance planning decisions. Prioritization becomes important in case of counter based maintenance when on a day the required maintenance tasks far exceed the available resources. Hence prioritization is important both from strategic planning as well as operational point of view. The prioritization in this paper is done using the AHPFuzzy-TOPSIS approach and the decision for classification, assigning appropriate service levels and appropriate action is left to the user based on the results obtained.

Work has been done in the recent past using $\mathrm{AI}$ in this field but most of the work is difficult to be understood by practicing managers and its application is limited. Also most of the work is in field of machines while very little attention has been provided to maintenance of tools and the specific environment in which they operate and become important to production and cost targets.

Genetic algorithm uses natural selection process but formulation of the problem is difficult for practicing managers. Also the business scenario may change from time to time and it might not make a close fit with evolutionary algorithm. In case of genetic algorithm operating with dynamic data set is difficult while fuzzy logic allows user to iterate with the changing business scenarios and also the problem formulation is comparatively less complex. Additionally fuzzy logic allows a greater degree of control both during problem formulation and solution allowing user to make suitable changes at various stages of problem.

In the current paper we propose a simple methodology which is easily understood, can be modified to include more criterion, change their values and the recommended actions are open to the user. This provides a robust model that can be easily modified to suit the user environment and can be improved over time to fit the needs more closely. 
Though fuzzy does not employ any parameters that require statistical significance method but with the increase in number of dimensional pattern, the number of possible fuzzy rules may become very large as it is exponential function of number of parameters. Hence there is a limitation on number of parameters that can be modelled while applying fuzzy based rules else the requirement of computational power will be overwhelming. The method is a decision support framework which allows user to build in the scenarios and evaluate the output to judiciously select the right alternative. The method finally gives a ranking thus allowing reduced complexity while decision making.

Considering the environment discussed in this section along with the research work done till now with respect to conventional and new maintenance techniques, the methodology of fuzzy-TOPSIS is selected to carry forward the work in the field of tool maintenance which has not been attempted yet. Next section entails the methodology selected.

\section{Methodology}

Though our focus is not on joint production-maintenance plan but it is important to provide some insights into this regarding the prioritization we propose. As we know that the auto components environment consists of a large number of tools and hence first cut needs to be done to concentrate on most important and critical tools.

The initial analysis needs to be done to classify tools into the three classes, viz., time based, counter based and time plus counter based, for the maintenance requirements. The classification can be done using ABC, VED or Pareto analysis. Time based tools are not that important for the prioritization since they can be scheduled for maintenance keeping in mind the available manpower, so resource levelling is not a big problem. It is the counter-based and counter plus time based tools that we would be focussed in further study.

The first step is to decide on the parameters that will be used for prioritization and classification. The parameters used in the study are taken from another research work of [18]. The parameters were for machinery but were found suitable for tools except one which was replaced by another parameter that was important in case of tools. The selected parameters are:

- Sensitivity of operations

- Mean time between failure

- Mean time to repair

- Availability of required part

- Availability of repair personnel

- Lead time

On the basis of AHP, weightages are assigned to each criterion. Then fuzzy value in triangular form is taken to find out weighted fuzzy value for each tool. Finally TOPSIS is applied to obtain final ranking. The fuzzy-TOPSIS method is described below as we have customized the method to fit to our requirements. Hence the basic method is explained in "Fuzzy TOPSIS Method" section while the modified version is explained in "Proposed Model" section along with the need for doing so.

\section{Fuzzy TOPSIS Method}

Triangular form of representation is used most widely for fuzzy numbers $[8,11,12,23]$. Some basic definitions related to Fuzzy sets are given below $[1,4,5,14,16,21,25]$ :

i. A fuzzy set $\widetilde{A}$ in a universe of discourse $\mathrm{X}$ is characterized by a membership function $\mu_{\mathrm{A}} \widetilde{A}$ which associates with each element $\mathrm{x}$ in $\mathrm{X}$ a real number in the interval $[0,1]$. The function value is termed the grade of membership of $\mathrm{x}$ in $\mathrm{A}$.

ii. A triangular fuzzy number $\mu_{\mathrm{a}}$ can be defined by a triplet (a1-a3) as shown in Fig. 1. The membership function $\mu_{A}(\mathrm{x})$ is defined as:

$\mu_{\mathrm{A}}(\mathrm{x})= \begin{cases}0, & x<0 \\ \frac{x-a_{1}}{a_{2}-a_{1}}, & a_{1}<x<a_{2} \\ \frac{x-a_{2}}{a_{3}-a_{2}}, & a_{2}<x<a_{3} \\ 0, & x>a_{3}\end{cases}$

Let $\widetilde{a}$ and $\widetilde{b}$ be two triangular fuzzy numbers parameterized by the triplet $\left(a_{1}, a_{2}, a_{3}\right)$ and $\left(b_{1}, b_{2}, b_{3}\right)$, respectively, then the operational laws of these two triangular fuzzy numbers are as follows:

$$
\begin{aligned}
\widetilde{a}+\widetilde{b} & =\left(a_{1}, a_{2}, a_{3}\right)+\left(b_{1}, b_{2}, b_{3}\right) \\
& =\left(a_{1}+b_{1}, a_{2}+b_{2}, a_{3}+b_{3}\right), \\
\widetilde{a}-\widetilde{b} & =\left(a_{1}, a_{2}, a_{3}\right)-\left(b_{1}, b_{2}, b_{3}\right) \\
& =\left(a_{1}-b_{1}, a_{2}-b_{2}, a_{3}-b_{3}\right),
\end{aligned}
$$

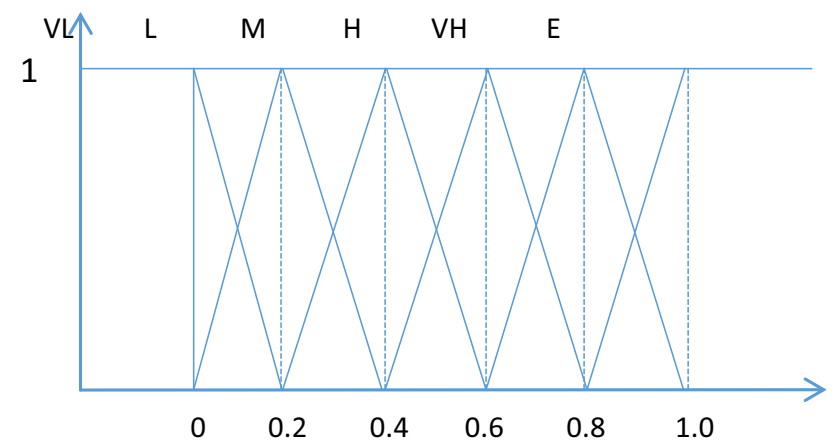

Fig. 1 Functions of linguistic variables 
Table 1 Triangular fuzzy values for various levels

\begin{tabular}{ll}
\hline Linguistic variable & Fuzzy numbers \\
\hline Very low & $(0,0,0.2)$ \\
Low & $(0,0.2,0.4)$ \\
Medium & $(0.2,0.4,0.6)$ \\
High & $(0.4,0.6,0.8)$ \\
Very high & $(0.6,0.8,1.0)$ \\
Excellent & $(0.8,1.0,1.0)$ \\
\hline
\end{tabular}

$$
\begin{aligned}
\widetilde{a} * \widetilde{b} & =\left(a_{1}, a_{2}, a_{3}\right) *\left(b_{1}, b_{2}, b_{3}\right) \\
& =\left(a_{1} * b_{1}, a_{2} * b_{2}, a_{3} * b_{3}\right), \\
\widetilde{a} / \widetilde{b} & =\left(a_{1}, a_{2}, a_{3}\right) /\left(b_{1}, b_{2}, b_{3}\right) \\
& =\left(a_{1} / b_{3}, a_{2} / b_{2}, a_{3} / b_{1}\right), \\
\widetilde{a} & =\left(k a_{1}, k a_{2}, k a_{3}\right),
\end{aligned}
$$

iii. A linguistic variable is a variable, values of which are in linguistic terms [2,24]. For too complex or poorly defined variables which are too difficult to be established quantitatively or to be well defined in conventional quantitative expressions, linguistic variables are very useful $[2,24]$. Fuzzy numbers can be used to represent these linguistic variables.

iv. Let $\widetilde{a}=\left(a_{1}, a_{2}, a_{3}\right)$ and $\widetilde{b}=\left(b_{1}, b_{2}, b_{3}\right)$ be two triangular fuzzy numbers, then the vertex method is defined to calculate the distance between them:

$$
d(\widetilde{a}, \widetilde{b})=\sqrt{\frac{1}{3}\left[\left(a_{1}-b_{1}\right)^{2}+\left(a_{2}-b_{2}\right)^{2}+\left(a_{3}-b_{3}\right)^{2}\right]}
$$

v. Considering the different importance values of each criterion, the weighted normalized fuzzy-decision matrix is constructed as:

$$
\widetilde{V}=\left[\widetilde{v}_{i j}\right]_{n \times j} \quad i=1,2,3, \ldots, n, \quad j=1,2,3, \ldots, J
$$

where $\widetilde{v}_{i j}=\widetilde{v}_{i j} \times w_{i}$.

A set of performance ratings of $A_{j}(j=1,2,3, \ldots, J)$ with respect to criteria $C_{i}(i=1,2,3, \ldots, n)$ is called $\widetilde{X}=$ $\left\{\widetilde{x}_{i j}, \quad i=1,2,3, \ldots, n, \quad j=1,2,3, \ldots, J\right\}$.

A set of importance weights of each criterion is $w_{i}(i=1,2,3, \ldots, n)$.

As per the fuzzy theory mentioned above, FUZZY TOPSIS used in this paper can be summarized as follows:

\section{Step 1}

Choose the linguistic variables $\left(\widetilde{x}_{i j}, i=1,2,3, \ldots, n, j=\right.$ $1,2,3, \ldots, J)$ for alternatives with respect to criteria. Fuzzy linguistic rating $\left(\widetilde{x}_{i j}\right)$ preserves the property that the ranges for normalized triangular fuzzy numbers belong to $[0,1]$; thus, there is no need of normalization.

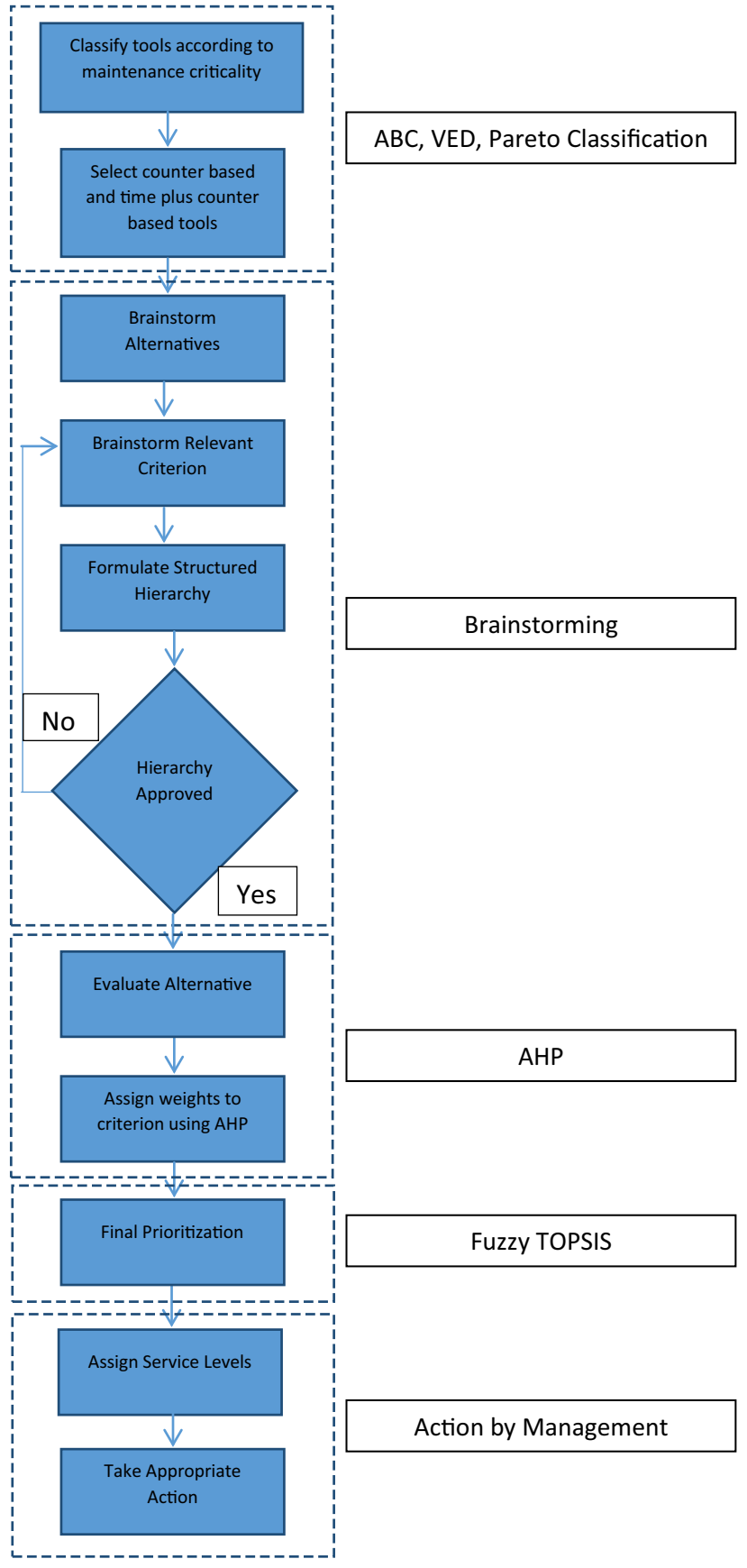

Fig. 2 Flowchart of activity

Step 2

Calculate the weighted normalized fuzzy decision matrix.

Step 3

Identify positive ideal $\left(A^{+}\right)$and negative ideal $\left(A^{-}\right)$solutions. The fuzzy positive ideal solution and negative ideal solutions are represented by following equations:

$A^{+}=\left\{\widetilde{v}_{1}^{+}, \widetilde{v}_{2}^{+}, \ldots, \widetilde{v}_{i}^{+}\right\}$ 
Table 2 Linguistic values for selected criterion for tools

\begin{tabular}{|c|c|c|c|c|c|c|}
\hline Tool no. & $\begin{array}{l}\text { Sensitivity of } \\
\text { operation }\end{array}$ & $\begin{array}{l}\text { Mean time between } \\
\text { failures (MTBF) }\end{array}$ & $\begin{array}{l}\text { Mean time to repair } \\
\text { (MTTR) }\end{array}$ & $\begin{array}{l}\text { Availability of required } \\
\text { parts (ARPa) }\end{array}$ & $\begin{array}{l}\text { Availability of repair } \\
\text { personnel (ARPe) }\end{array}$ & $\begin{array}{l}\text { Lead time } \\
\text { (LT) }\end{array}$ \\
\hline 1 & VL & VH & $\mathrm{H}$ & $\mathrm{VH}$ & $\mathrm{L}$ & $\mathrm{H}$ \\
\hline 2 & M & $\mathrm{H}$ & M & $\mathrm{H}$ & M & $\mathrm{H}$ \\
\hline 3 & $\mathrm{E}$ & $\mathrm{VH}$ & $\mathrm{H}$ & $\mathrm{L}$ & $\mathrm{L}$ & $\mathrm{H}$ \\
\hline 4 & $\mathrm{~L}$ & M & M & $\mathrm{VH}$ & VL & $\mathrm{H}$ \\
\hline 5 & VH & $\mathrm{VH}$ & $\mathrm{H}$ & $\mathrm{L}$ & $\mathrm{E}$ & $\mathrm{L}$ \\
\hline 6 & M & $\mathrm{H}$ & M & VL & $\mathrm{H}$ & $\mathrm{H}$ \\
\hline 7 & $\mathrm{H}$ & $\mathrm{E}$ & $\mathrm{VH}$ & $\mathrm{H}$ & M & VH \\
\hline 8 & $\mathrm{H}$ & M & $\mathrm{H}$ & $\mathrm{L}$ & $\mathrm{L}$ & $\mathrm{L}$ \\
\hline 9 & $\mathrm{H}$ & $\mathrm{VH}$ & $\mathrm{VH}$ & $\mathrm{L}$ & VL & VH \\
\hline 10 & $\mathrm{M}$ & $\mathrm{M}$ & $\mathrm{H}$ & $\mathrm{L}$ & VH & $\mathrm{L}$ \\
\hline 11 & VH & $\mathrm{VH}$ & $\mathrm{E}$ & $\mathrm{VH}$ & $\mathrm{L}$ & VH \\
\hline 12 & M & $\mathrm{H}$ & $\mathrm{H}$ & $\mathrm{E}$ & $\mathrm{H}$ & $\mathrm{L}$ \\
\hline 13 & $\mathrm{~L}$ & $\mathrm{E}$ & $\mathrm{L}$ & $\mathrm{H}$ & $\mathrm{H}$ & $\mathrm{L}$ \\
\hline 14 & $\mathrm{~L}$ & $\mathrm{~L}$ & VL & $\mathrm{L}$ & $\mathrm{L}$ & VL \\
\hline 15 & VL & VL & $\mathrm{L}$ & M & $\mathrm{L}$ & M \\
\hline 16 & $\mathrm{~L}$ & $\mathrm{~L}$ & VL & M & M & M \\
\hline 17 & $\mathrm{H}$ & & VL & $\mathrm{L}$ & M & $\mathrm{L}$ \\
\hline 18 & $\mathrm{~L}$ & $\mathrm{~L}$ & VL & $\mathrm{H}$ & M & $\mathrm{H}$ \\
\hline 19 & $\mathrm{E}$ & M & M & M & VH & $\mathrm{L}$ \\
\hline 20 & M & $\mathrm{L}$ & VL & M & VL & $\mathrm{H}$ \\
\hline 21 & M & M & $\mathrm{L}$ & $\mathrm{L}$ & $\mathrm{L}$ & M \\
\hline 22 & VH & M & M & VL & $\mathrm{H}$ & M \\
\hline 23 & M & M & $\mathrm{L}$ & M & $\mathrm{L}$ & M \\
\hline 24 & $\mathrm{~L}$ & $\mathrm{E}$ & $\mathrm{M}$ & $\mathrm{M}$ & $\mathrm{E}$ & VL \\
\hline 25 & $\mathrm{H}$ & $\mathrm{M}$ & $\mathrm{L}$ & $\mathrm{H}$ & $\mathrm{M}$ & E \\
\hline 26 & $\mathrm{H}$ & $\mathrm{E}$ & $\mathrm{H}$ & $\mathrm{VH}$ & VL & $\mathrm{M}$ \\
\hline 27 & $\mathrm{~L}$ & $\mathrm{M}$ & $\mathrm{L}$ & VL & VH & $\mathrm{H}$ \\
\hline 28 & $\mathrm{M}$ & $\mathrm{L}$ & $\mathrm{L}$ & $\mathrm{M}$ & $\mathrm{L}$ & VL \\
\hline 29 & VH & $\mathrm{L}$ & VL & $\mathrm{M}$ & $\mathrm{M}$ & $\mathrm{H}$ \\
\hline 30 & $\mathrm{E}$ & VL & $\mathrm{M}$ & $\mathrm{H}$ & VL & VL \\
\hline
\end{tabular}

$$
\begin{aligned}
= & \left\{(\underbrace{\max v_{i j}}_{j} \mid \forall i \in Z^{\prime}),(\underbrace{\min v_{i j}}_{j} \mid \forall i \in Z^{\prime \prime})\right\}, \\
& i=1,2,3, \ldots, n, j \\
= & 1,2,3, \ldots, J \\
A^{-}= & \left\{\widetilde{v}_{1}^{+}, \widetilde{v}_{2}^{+}, \ldots, \widetilde{v}_{i}^{+}\right\} \\
= & \left\{(\underbrace{\min v_{i j}}_{j} \mid \forall i \in Z^{\prime}),(\underbrace{\max v_{i j}}_{j} \mid \forall i \in Z^{\prime \prime})\right\}, \\
& i=1,2,3, \ldots, n, j \\
= & 1,2,3, \ldots, J
\end{aligned}
$$

where $Z^{\prime}$ is related to benefit criteria and $Z^{\prime \prime}$ is related to cost criteria
Step 4

Calculate the distance of each alternative from $A^{+}$and $A^{-}$ as follows

$$
\begin{aligned}
& D_{j}^{+}=\sum_{j=1}^{n} d\left(\widetilde{v}_{i j}, \widetilde{v}_{i}^{+}\right), \quad j=1,2,3, \ldots, J \\
& D_{j}^{-}=\sum_{j=1}^{n} d\left(\widetilde{v}_{i j}, \widetilde{v}_{i}^{-}\right), \quad j=1,2,3, \ldots, J
\end{aligned}
$$

Step 5

Calculate the similarities to ideal solution. 
Step 6

On the basis of $Z Z_{j}$ score, rank the alternatives.

\section{Proposed Model}

The proposed model consists of three parts:

(1) Identification of criterion for selection of tools for maintenance

(2) Use of AHP to weight the criterion

(3) Evaluate the alternatives using Fuzzy TOPSIS

The criterion to be selected forms the backbone of the procedure. Wrong selection of criterion may fail the entire purpose of the study however accurate it may be. Therefore selection of criterion needs to be given utmost priority and should be brainstormed. In our study, we considered a number of literature and found out the criterion that best fits the model we are proposing. As it is already discussed that most of the study is based on maintenance of machines and very less is available on tools, we have modified the criterion to fit the tool study. The criteria selected [18] for the study are:

(1) Sensitivity of operation

(2) Mean time between failures (MTBF)

(3) Mean time to repair (MTTR)

(4) Availability of required parts (ARPa)

(5) Availability of repair personnel (ARPe)

(6) Lead time (LT)

Though above criteria are used in formulating the problem, the management can decide on additional or can substitute the criterion for some other that is more relevant to their business scenario. After the criteria are selected and approved, next step is to weigh them according to their importance. AHP is used for assigning weight to the listed criteria. Finally fuzzy TOPSIS is used to determine the ranks. Triangular Fuzzy values, given in Table 1, are used in the evaluation using the linguistic values. The final prioritization is done on the basis of maximised value of $\mathrm{ZZ}_{\mathrm{j}}$.

Use of fuzzy allows user to iterate with both the number of levels and the weightage assigned to each linguistic variable. In this paper we have used triangular fuzzy values which can be easily replaced by fuzzy variables having more dimensions in case the number of decision variables is more. Also the values assigned can be changed on the basis of the data captured on ground. Hence use of fuzzy provides flexibility in terms of adapting to various scenarios a business experiences in reality.

In the present approach of using Fuzzy TOPSIS, we need to arrive at a positive and negative ideal value of cost and benefit criteria both. In general, for cost criteria, the positive ideal value is the lowest one and negative ideal value is the highest one because we want to minimize the cost.

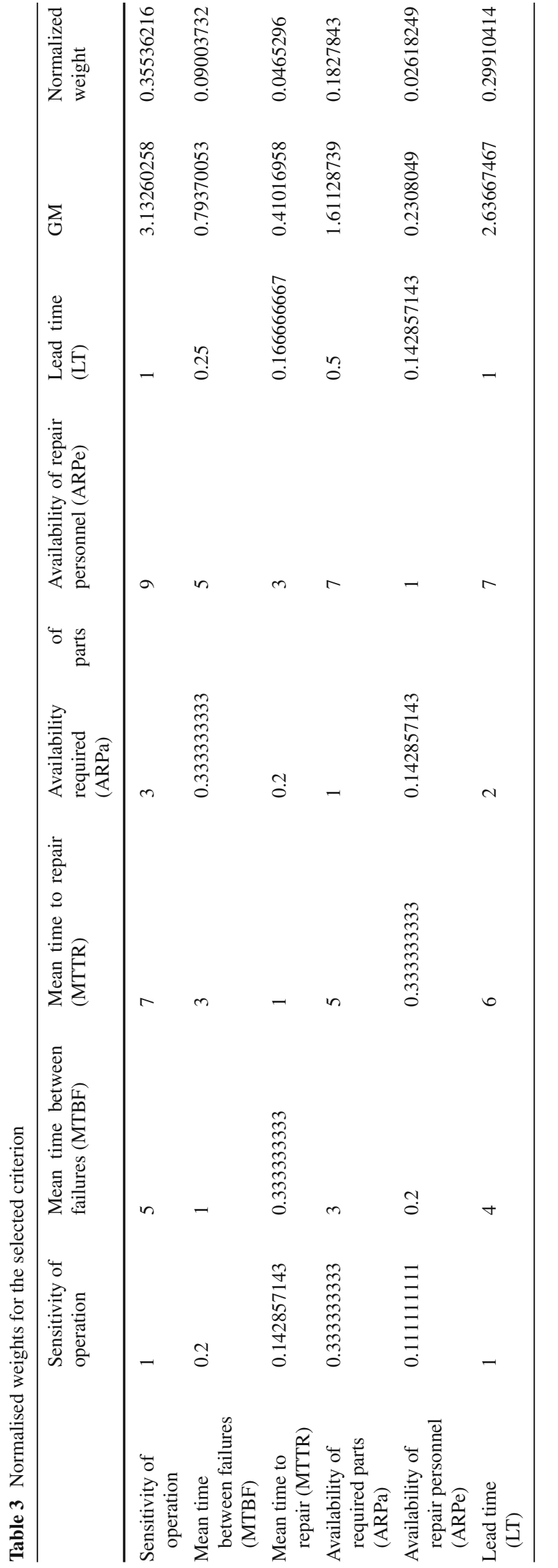


Table 4 Fuzzy values for selected tools along with criterion weights

\begin{tabular}{|c|c|c|c|c|c|c|}
\hline Tool no. & $\begin{array}{l}\text { Sensitivity of } \\
\text { operation }\end{array}$ & $\begin{array}{l}\text { Mean time between } \\
\text { failures (MTBF) }\end{array}$ & $\begin{array}{l}\text { Mean time to repair } \\
\text { (MTTR) }\end{array}$ & $\begin{array}{l}\text { Availability of required } \\
\text { parts (ARPa) }\end{array}$ & $\begin{array}{l}\text { Availability of repair } \\
\text { personnel (ARPe) }\end{array}$ & Lead time (LT) \\
\hline Weights & 0.355362158 & 0.090037317 & 0.046529601 & 0.182784298 & 0.026182487 & 0.299104139 \\
\hline 1 & $(0,0,0.2)$ & $(0.6,0.8,1)$ & $(0.4,0.6,0.8)$ & $(0.6,0.8,1)$ & $(0,0.2,0.4)$ & $(0.4,0.6,0.8)$ \\
\hline 2 & $(0.2,0.4,0.6)$ & $(0.4,0.6,0.8)$ & $(0.2,0.4,0.6)$ & $(0.4,0.6,0.8)$ & $(0.2,0.4,0.6)$ & $(0.4,0.6,0.8)$ \\
\hline 3 & $(0.8,1,1)$ & $(0.6,0.8,1)$ & $(0.4,0.6,0.8)$ & $(0,0.2,0.4)$ & $(0,0.2,0.4)$ & $(0.4,0.6,0.8)$ \\
\hline 4 & $(0,0.2,0.4)$ & $(0.2,0.4,0.6)$ & $(0.2,0.4,0.6)$ & $(0.6,0.8,1)$ & $(0,0,0.2)$ & $(0.4,0.6,0.8)$ \\
\hline 5 & $(0.6,0.8,1)$ & $(0.6,0.8,1)$ & $(0.4,0.6,0.8)$ & $(0,0.2,0.4)$ & $(0.8,1,1)$ & $(0,0.2,0.4)$ \\
\hline 6 & $(0.2,0.4,0.6)$ & $(0.4,0.6,0.8)$ & $(0.2,0.4,0.6)$ & $(0,0,0.2)$ & $(0.4,0.6,0.8)$ & $(0.4,0.6,0.8)$ \\
\hline 7 & $(0.4,0.6,0.8)$ & $(0.8,1,1)$ & $(0.6,0.8,1)$ & $(0.4,0.6,0.8)$ & $(0.2,0.4,0.6)$ & $(0.6,0.8,1)$ \\
\hline 8 & $(0.4,0.6,0.8)$ & $(0.2,0.4,0.6)$ & $(0.4,0.6,0.8)$ & $(0,0.2,0.4)$ & $(0,0.2,0.4)$ & $(0,0.2,0.4)$ \\
\hline 9 & $(0.4,0.6,0.8)$ & $(0.6,0.8,1)$ & $(0.6,0.8,1)$ & $(0.2,0.4,0.6)$ & $(0,0,0.2)$ & $(0.6,0.8,1)$ \\
\hline 10 & $(0.2,0.4,0.6)$ & $(0.2,0.4,0.6)$ & $(0.4,0.6,0.8)$ & $(0,0.2,0.4)$ & $(0.6,0.8,1)$ & $(0,0.2,0.4)$ \\
\hline 11 & $(0.6,0.8,1)$ & $(0.6,0.8,1)$ & $(0.8,1,1)$ & $(0.6,0.8,1)$ & $(0,0.2,0.4)$ & $(0.6,0.8,1)$ \\
\hline 12 & $(0.2,0.4,0.6)$ & $(0.4,0.6,0.8)$ & $(0.4,0.6,0.8)$ & $(0.8,1,1)$ & $(0.4,0.6,0.8)$ & $(0.2,0.4,0.6)$ \\
\hline 13 & $(0,0.2,0.4)$ & $(0.8,1,1)$ & $(0,0.2,0.4)$ & $(0.4,0.6,0.8)$ & $(0.4,0.6,0.8)$ & $(0,0.2,0.4)$ \\
\hline 14 & $(0,0.2,0.4)$ & $(0,0.2,0.4)$ & $(0,0,0.2)$ & $(0,0.2,0.4)$ & $(0,0.2,0.4)$ & $(0,0,0.2)$ \\
\hline 15 & $(0,0,0.2)$ & $(0,0,0.2)$ & $(0.2,0.4,0.6)$ & $(0.2,0.4,0.6)$ & $(0,0.2,0.4)$ & $(0.2,0.4,0.6)$ \\
\hline 16 & $(0,0.2,0.4)$ & $(0,0.2,0.4)$ & $(0,0,0.2)$ & $(0.2,0.4,0.6)$ & $(0.2,0.4,0.6)$ & $(0.2,0.4,0.6)$ \\
\hline 17 & $(0.4,0.6,0.8)$ & $(0.2,0.4,0.6)$ & $(0,0,0.2)$ & $(0,0.2,0.4)$ & $(0.2,0.4,0.6)$ & $(0,0.2,0.4)$ \\
\hline 18 & $(0,0.2,0.4)$ & $(0,0.2,0.4)$ & $(0,0,0.2)$ & $(0.4,0.6,0.8)$ & $(0.2,0.4,0.6)$ & $(0.4,0.6,0.8)$ \\
\hline 19 & $(0.8,1,1)$ & $(0.2,0.4,0.6)$ & $(0.2,0.4,0.6)$ & $(0.2,0.4,0.6)$ & $(0.6,0.8,1)$ & $(0,0.2,0.4)$ \\
\hline 20 & $(0.2,0.4,0.6)$ & $(0.2,0.4,0.6)$ & $(0,0,0.2)$ & $(0.2,0.4,0.6)$ & $(0,0,0.2)$ & $(0.4,0.6,0.8)$ \\
\hline 21 & $(0.2,0.4,0.6)$ & $(0.2,0.4,0.6)$ & $(0,0.2,0.4)$ & $(0,0.2,0.4)$ & $(0,0.2,0.4)$ & $(0.2,0.4,0.6)$ \\
\hline 22 & $(0.6,0.8,1)$ & $(0.2,0.4,0.6)$ & $(0.2,0.4,0.6)$ & $(0,0,0.2)$ & $(0.4,0.6,0.8)$ & $(0.2,0.4,0.6)$ \\
\hline 23 & $(0.2,0.4,0.6)$ & $(0.2,0.4,0.6)$ & $(0,0.2,0.4)$ & $(0.2,0.4,0.6)$ & $(0,0.2,0.4)$ & $(0.2,0.4,0.6)$ \\
\hline 24 & $(0,0.2,0.4)$ & $(0.8,1,1)$ & $(0,0.2,0.4)$ & $(0.2,0.4,0.6)$ & $(0.8,1,1)$ & $(0,0,0.2)$ \\
\hline 25 & $(0.4,0.6,0.8)$ & $(0.2,0.4,0.6)$ & $(0.2,0.4,0.6)$ & $(0.4,0.6,0.8)$ & $(0.2,0.4,0.6)$ & $(0.8,1,1)$ \\
\hline 26 & $(0.4,0.6,0.8)$ & $(0.8,1,1)$ & $(0.4,0.6,0.8)$ & $(0.6,0.8,1)$ & $(0,0,0.2)$ & $(0.2,0.4,0.6)$ \\
\hline 27 & $(0,0.2,0.4)$ & $(0.2,0.4,0.6)$ & $(0,0.2,0.4)$ & $(0,0,0.2)$ & $(0.6,0.8,1)$ & $(0.4,0.6,0.8)$ \\
\hline 28 & $(0.2,0.4,0.6)$ & $(0,0.2,0.4)$ & $(0,0.2,0.4)$ & $(0.2,0.4,0.6)$ & $(0,0.2,0.4)$ & $(0,0,0.2)$ \\
\hline 29 & $(0.6,0.8,1)$ & $(0,0.2,0.4)$ & $(0,0,0.2)$ & $(0.2,0.4,0.6)$ & $(0.2,0.4,0.6)$ & $(0.4,0.6,0.8)$ \\
\hline 30 & $(0.8,1,1)$ & $(0,0,0.2)$ & $(0.2,0.4,0.6)$ & $(0.4,0.6,0.8)$ & $(0,0,0.2)$ & $(0,0,0.2)$ \\
\hline
\end{tabular}

Similarly for benefit criteria, the ideal positive value is the one with maximum value and for negative ideal value; it is the one with lowest value. However, in this paper we have taken the opposite. For example, Lead time is cost criteria, since we require shorter lead time for our tools, but a tool having low lead time will be less critical and the method will upgrade its rank at lower value of lead time because it satisfies the lower cost criteria. But we want the tool of low lead time to be lower in ranks in terms of criticality, therefore, in case of criticality, we have changed the ideal value to opposite.

Hence, in our case we have taken a higher value in cost criteria as positive ideal value and lower value in cost criteria as negative ideal value. Similarly for benefit criteria the ideal values are replaced. Thereby, we got the final modified equation for the calculation of positive and negative ideal values as follows:

$$
\begin{aligned}
A^{+}= & \left\{\widetilde{v}_{1}^{+}, \widetilde{v}_{2}^{+}, \ldots, \widetilde{v}_{i}^{+}\right\} \\
= & \left\{(\underbrace{\min v_{i j}}_{j} \mid \forall i \in Z^{\prime}),(\underbrace{\max v_{i j}}_{j} \mid \forall i \in Z^{\prime \prime})\right\}, \\
& i=1,2,3, \ldots, n, j \\
= & 1,2,3, \ldots, J
\end{aligned}
$$




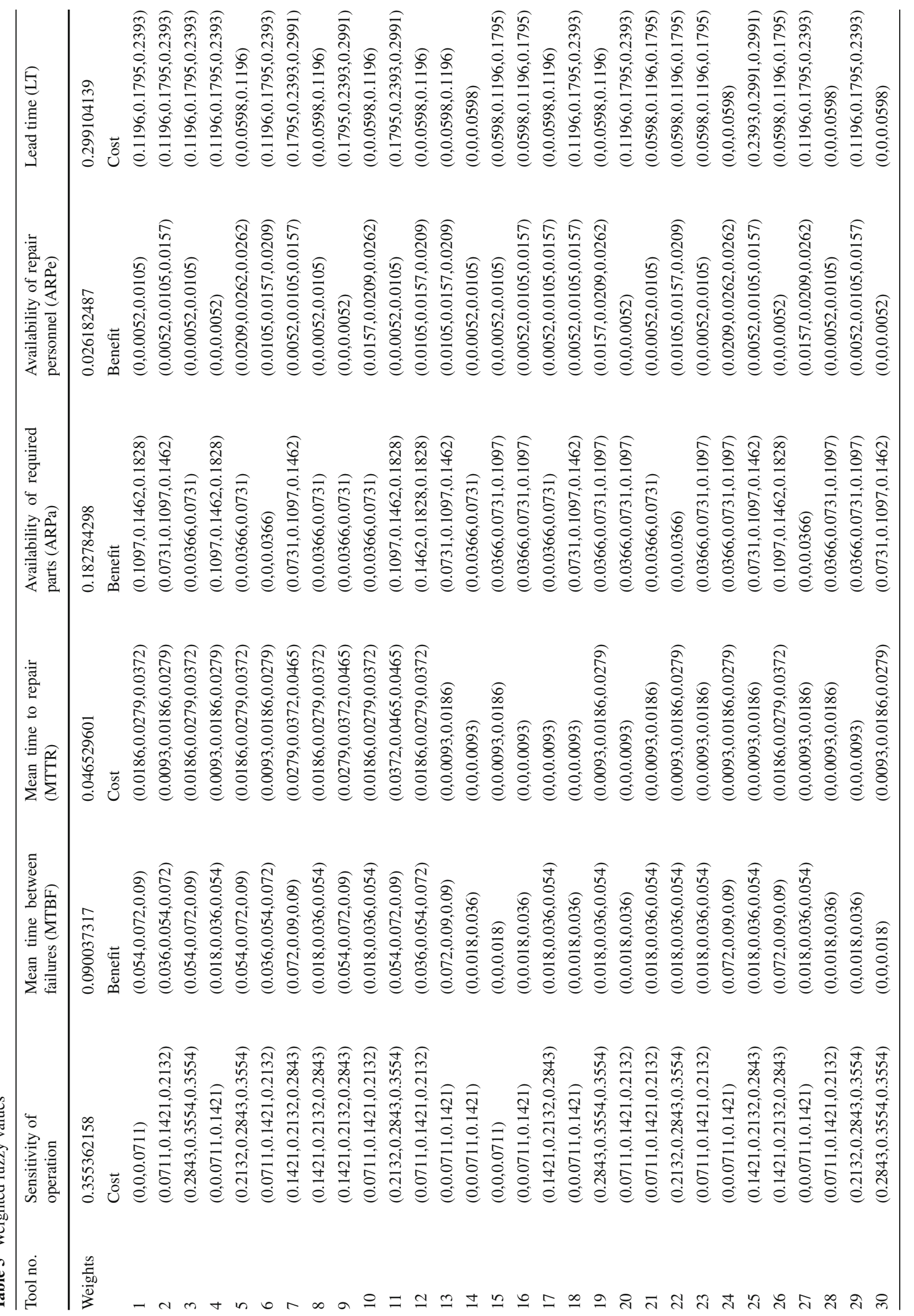


Table 6 Calculated $Z Z_{j}$ values

\begin{tabular}{|c|c|c|c|c|c|c|c|c|c|c|c|c|c|c|c|}
\hline \multirow[t]{3}{*}{ Tool no. } & \multicolumn{6}{|c|}{ Calculation for D+ } & \multirow[t]{3}{*}{$\mathrm{D}+$} & \multicolumn{6}{|c|}{ Calculation for D- } & \multirow[t]{3}{*}{ D- } & \multirow[t]{3}{*}{$\mathrm{ZZ}_{\mathrm{j}}$} \\
\hline & \multicolumn{6}{|c|}{ Criterion } & & \multicolumn{6}{|c|}{ Criterion } & & \\
\hline & 1 & 2 & 3 & 4 & 5 & 6 & & 1 & 2 & 3 & 4 & 5 & 6 & & \\
\hline 1 & 0.977 & 0.073 & 0.972 & 0.149 & 0.007 & 0.822 & 3.000 & 0.041 & 0.928 & 0.029 & 0.854 & 0.995 & 0.186 & 3.033 & 0.503 \\
\hline 2 & 0.860 & 0.056 & 0.981 & 0.114 & 0.011 & 0.822 & 2.844 & 0.154 & 0.946 & 0.020 & 0.891 & 0.990 & 0.186 & 3.186 & 0.528 \\
\hline 3 & 0.669 & 0.073 & 0.972 & 0.047 & 0.007 & 0.822 & 2.591 & 0.333 & 0.928 & 0.029 & 0.964 & 0.995 & 0.186 & 3.435 & 0.570 \\
\hline 4 & 0.931 & 0.039 & 0.981 & 0.149 & 0.003 & 0.822 & 2.925 & 0.092 & 0.964 & 0.020 & 0.854 & 0.998 & 0.186 & 3.114 & 0.516 \\
\hline 5 & 0.718 & 0.073 & 0.972 & 0.047 & 0.025 & 0.941 & 2.777 & 0.290 & 0.928 & 0.029 & 0.964 & 0.976 & 0.077 & 3.264 & 0.540 \\
\hline 6 & 0.860 & 0.056 & 0.981 & 0.021 & 0.016 & 0.822 & 2.757 & 0.154 & 0.946 & 0.020 & 0.988 & 0.984 & 0.186 & 3.278 & 0.543 \\
\hline 7 & 0.789 & 0.084 & 0.963 & 0.114 & 0.011 & 0.762 & 2.723 & 0.221 & 0.916 & 0.038 & 0.891 & 0.990 & 0.244 & 3.300 & 0.548 \\
\hline 8 & 0.789 & 0.039 & 0.972 & 0.047 & 0.007 & 0.941 & 2.795 & 0.221 & 0.964 & 0.029 & 0.964 & 0.995 & 0.077 & 3.250 & 0.538 \\
\hline 9 & 0.789 & 0.073 & 0.963 & 0.047 & 0.003 & 0.762 & 2.638 & 0.221 & 0.928 & 0.038 & 0.964 & 0.998 & 0.244 & 3.393 & 0.563 \\
\hline 10 & 0.860 & 0.039 & 0.972 & 0.047 & 0.021 & 0.941 & 2.881 & 0.154 & 0.964 & 0.029 & 0.964 & 0.979 & 0.077 & 3.167 & 0.524 \\
\hline 11 & 0.718 & 0.073 & 0.957 & 0.149 & 0.007 & 0.762 & 2.666 & 0.290 & 0.928 & 0.044 & 0.854 & 0.995 & 0.244 & 3.355 & 0.557 \\
\hline 12 & 0.860 & 0.056 & 0.972 & 0.171 & 0.016 & 0.941 & 3.017 & 0.154 & 0.946 & 0.029 & 0.830 & 0.984 & 0.077 & 3.020 & 0.500 \\
\hline 13 & 0.931 & 0.084 & 0.991 & 0.114 & 0.016 & 0.941 & 3.077 & 0.092 & 0.916 & 0.012 & 0.891 & 0.984 & 0.077 & 2.972 & 0.491 \\
\hline 14 & 0.931 & 0.023 & 0.997 & 0.047 & 0.007 & 0.980 & 2.985 & 0.092 & 0.982 & 0.005 & 0.964 & 0.995 & 0.035 & 3.072 & 0.507 \\
\hline 15 & 0.977 & 0.010 & 0.991 & 0.079 & 0.007 & 0.882 & 2.945 & 0.041 & 0.994 & 0.012 & 0.927 & 0.995 & 0.129 & 3.098 & 0.513 \\
\hline 16 & 0.931 & 0.023 & 0.997 & 0.079 & 0.011 & 0.882 & 2.923 & 0.092 & 0.982 & 0.005 & 0.927 & 0.990 & 0.129 & 3.125 & 0.517 \\
\hline 17 & 0.789 & 0.039 & 0.997 & 0.047 & 0.011 & 0.941 & 2.825 & 0.221 & 0.964 & 0.005 & 0.964 & 0.990 & 0.077 & 3.221 & 0.533 \\
\hline 18 & 0.931 & 0.023 & 0.997 & 0.114 & 0.011 & 0.822 & 2.898 & 0.092 & 0.982 & 0.005 & 0.891 & 0.990 & 0.186 & 3.146 & 0.520 \\
\hline 19 & 0.669 & 0.039 & 0.981 & 0.079 & 0.021 & 0.941 & 2.731 & 0.333 & 0.964 & 0.020 & 0.927 & 0.979 & 0.077 & 3.301 & 0.547 \\
\hline 20 & 0.860 & 0.023 & 0.997 & 0.079 & 0.003 & 0.822 & 2.784 & 0.154 & 0.982 & 0.005 & 0.927 & 0.998 & 0.186 & 3.253 & 0.539 \\
\hline 21 & 0.860 & 0.039 & 0.991 & 0.047 & 0.007 & 0.882 & 2.825 & 0.154 & 0.964 & 0.012 & 0.964 & 0.995 & 0.129 & 3.218 & 0.532 \\
\hline 22 & 0.718 & 0.039 & 0.981 & 0.021 & 0.016 & 0.882 & 2.657 & 0.290 & 0.964 & 0.020 & 0.988 & 0.984 & 0.129 & 3.376 & 0.560 \\
\hline 23 & 0.860 & 0.039 & 0.991 & 0.079 & 0.007 & 0.882 & 2.857 & 0.154 & 0.964 & 0.012 & 0.927 & 0.995 & 0.129 & 3.181 & 0.527 \\
\hline 24 & 0.931 & 0.084 & 0.981 & 0.079 & 0.025 & 0.980 & 3.081 & 0.092 & 0.916 & 0.020 & 0.927 & 0.976 & 0.035 & 2.965 & 0.490 \\
\hline 25 & 0.789 & 0.039 & 0.991 & 0.114 & 0.011 & 0.721 & 2.665 & 0.221 & 0.964 & 0.012 & 0.891 & 0.990 & 0.281 & 3.358 & 0.558 \\
\hline 26 & 0.789 & 0.084 & 0.972 & 0.149 & 0.003 & 0.882 & 2.879 & 0.221 & 0.916 & 0.029 & 0.854 & 0.998 & 0.129 & 3.148 & 0.522 \\
\hline 27 & 0.931 & 0.039 & 0.991 & 0.021 & 0.021 & 0.822 & 2.825 & 0.092 & 0.964 & 0.012 & 0.988 & 0.979 & 0.186 & 3.221 & 0.533 \\
\hline 28 & 0.860 & 0.023 & 0.991 & 0.079 & 0.007 & 0.980 & 2.940 & 0.154 & 0.982 & 0.012 & 0.927 & 0.995 & 0.035 & 3.104 & 0.514 \\
\hline 29 & 0.718 & 0.023 & 0.997 & 0.079 & 0.011 & 0.822 & 2.650 & 0.290 & 0.982 & 0.005 & 0.927 & 0.990 & 0.186 & 3.381 & 0.561 \\
\hline 30 & 0.669 & 0.010 & 0.981 & 0.114 & 0.003 & 0.980 & 2.758 & 0.333 & 0.994 & 0.020 & 0.891 & 0.998 & 0.035 & 3.271 & 0.543 \\
\hline
\end{tabular}

$$
\begin{aligned}
A^{-}= & \left\{\widetilde{v}_{1}^{+}, \widetilde{v}_{2}^{+}, \ldots, \widetilde{v}_{i}^{+}\right\} \\
= & \left\{(\underbrace{\max v_{i j}}_{j} \mid \forall i \in Z^{\prime}),(\underbrace{\min v_{i j}}_{j} \mid \forall i \in Z^{\prime \prime})\right\}, \\
& i=1,2,3, \ldots, n, j \\
= & 1,2,3, \ldots, J
\end{aligned}
$$

where $Z^{\prime}$ is related to benefit criteria and $Z^{\prime \prime}$ is related to cost criteria

The selected triangular values are listed in Table 1.

Figure 1 depicts the triangular fuzzy value in diagrammatic form. The flowchart for entire process of finding out the priority is described in Fig. 2. It also details the various methods used at each stage.

The environment we selected for study consists of more than 1200 tools out of which we selected 30 most important tools as counter based and counter plus time based. For these 30 tools linguistic values are assigned against the criterion selected. Though the work was carried out for 30 tools only, it can be extended to include any number of tools. Table 2 lists the linguistic values for each of the selected criterion for each tool.

Table 3 depicts the rating on likert scale provided to various selected criteria and the final normalized weights obtained as a result of AHP procedure. 
Table 7 Final rankings

\begin{tabular}{|c|c|c|c|c|}
\hline Tool ID & $\mathrm{D}+$ & $\mathrm{D}-$ & $\mathrm{ZZ}_{\mathrm{j}}$ & Tool final ranking \\
\hline 3 & 2.590705 & 3.435092 & 0.570064 & 1 \\
\hline 9 & 2.63772 & 3.393441 & 0.562651 & 2 \\
\hline 29 & 2.650484 & 3.380536 & 0.560525 & 3 \\
\hline 22 & 2.657481 & 3.375858 & 0.559534 & 4 \\
\hline 25 & 2.664902 & 3.358043 & 0.557542 & 5 \\
\hline 11 & 2.666423 & 3.355198 & 0.557192 & 6 \\
\hline 7 & 2.723427 & 3.299575 & 0.547829 & 7 \\
\hline 19 & 2.731276 & 3.301216 & 0.547239 & 8 \\
\hline 6 & 2.756602 & 3.277981 & 0.543199 & 9 \\
\hline 30 & 2.758091 & 3.271144 & 0.542547 & 10 \\
\hline 5 & 2.776891 & 3.263865 & 0.540307 & 11 \\
\hline 20 & 2.783951 & 3.252613 & 0.538819 & 12 \\
\hline 8 & 2.795383 & 3.249862 & 0.53759 & 13 \\
\hline 17 & 2.824709 & 3.221083 & 0.532781 & 14 \\
\hline 27 & 2.824843 & 3.220884 & 0.532754 & 15 \\
\hline 21 & 2.825125 & 3.217535 & 0.53247 & 16 \\
\hline 2 & 2.844172 & 3.186098 & 0.528351 & 17 \\
\hline 23 & 2.856914 & 3.180987 & 0.526837 & 18 \\
\hline 10 & 2.880873 & 3.166716 & 0.523633 & 19 \\
\hline 26 & 2.879467 & 3.147703 & 0.522252 & 20 \\
\hline 18 & 2.897843 & 3.145594 & 0.520498 & 21 \\
\hline 16 & 2.922911 & 3.125336 & 0.516734 & 22 \\
\hline 4 & 2.925294 & 3.114499 & 0.515663 & 23 \\
\hline 28 & 2.940018 & 3.104281 & 0.513588 & 24 \\
\hline 15 & 2.945471 & 3.098444 & 0.512655 & 25 \\
\hline 14 & 2.985326 & 3.072414 & 0.507188 & 26 \\
\hline 1 & 3.000489 & 3.033146 & 0.502706 & 27 \\
\hline 12 & 3.017121 & 3.019635 & 0.500208 & 28 \\
\hline 13 & 3.077285 & 2.972128 & 0.491308 & 29 \\
\hline 24 & 3.08062 & 2.96531 & 0.490464 & 30 \\
\hline
\end{tabular}

Table 4 lists the triangular fuzzy value assigned to each tool for each of the selected criterion. They are the quantification of linguistic values described in Table 2.

Table 5 contains the weighted fuzzy values which are obtained by taking joint effect of weights of various criterions along with the triangular fuzzy value.

Table 6 lists the positive as well as the negative ideal solutions on the basis of TOPSIS methodology and the final score which will decide the priority ranking.

Table 7 sums up the entire procedure by assigning the final ranking to the maintenance priority of tools. On the basis of this, a decision can be taken by the management to allocate resources.

\section{Conclusion and Future Scope}

The results obtained can be used for recommendations and future action by the management. On the basis of ranking, on a given constraint day tools can be selected for maintenance which is most critical to operations. Also on the basis of this ranking content and frequency of maintenance can be determined which can help in estimation of maintenance manpower requirement. One important aspect that can be further studied is how to integrate the maintenance plan for time based tools, which was created separately (as they are not part of this analysis) with the maintenance plan for counter based tools created on the basis of results obtained. But obvious is the fact that some algorithm that proposes a joint maintenance-production plan needs to be integrated along with the results obtained to ensure a truly integrated production-maintenance plan. Additionally, one of the problem that maintenance management faces is the assignment of service levels for different tools. As we are aware that the reliability of tools as well as machine decreases as their usage increases, in order to avoid any breakdown, generally MTTF is calculated and on the basis of that maintenance schedule is prepared. But in actual scenario, the equipment may fail before or after the mean as expressed by standard deviation of mean. Hence in order to avoid any such failure tolerances needs to be provided, assigning service levels as one of the methods of ensuring it. Thus on the basis of the priority obtained service levels can be assigned, providing for larger tolerances to tools which are of higher ranking (more critical). In this way we can optimise the resources by applying proper service levels according to the criticality of the tool to the production environment.

\section{References}

1. Chen, S.M.: Evaluating weapon systems using fuzzy arithmetic operations. Fuzzy Sets Syst. 77, 265-276 (1996)

2. Chen, C.T.: Extensions of the TOPSIS for group decision-making under fuzzy environment. Fuzzy Sets Syst. 114, 1-9 (2000)

3. Chen, X., Yang, Y., Lee, L., Ni, J.: Optimization consideration of the intelligent maintenance system. In: Proceedings of 5th International Conference on Managing Innovations in Manufacturing (MIM), Milwaukee, 9-11 September 2002

4. Chen, C.T., Lin, C.T., Huang, S.F.: A fuzzy approach for supplier evaluation and selection in supply chain management. Int. J. Prod. Econ. 102, 289-301 (2006)

5. Cheng, C.H., Lin, Y.: Evaluating the best main battle tank using fuzzy decision theory with linguistic criteria evaluation. Eur. J. Oper. Res. 142, 174-186 (2002)

6. Ciarapica, F.E., Giacchetta, G.: Managing the condition-based maintenance of a combined-cycle power plant: an approach using soft computing techniques. J. Loss Prev. Process. Ind. 19, 316-325 (2006)

7. Cross, M.: Raising the value of maintenance in the corporate environment. Manag. Res. News 11(3), 8-11 (1988)

8. Ding, J.F., Liang, G.S.: Using fuzzy MCDM to select partners of strategic alliances for liner shipping. Inf. Sci. 173, 197-225 (2005)

9. Duffuaa, S.O., Al-Sultan, K.S.: Mathematical programming approaches for the management of maintenance planning and scheduling. J. Qual. Maint. Eng. 3(3), 163-176 (1997) 
10. Gopalakrishnan, M., Mohan, S., He, Z.: A tabu search heuristic for preventive maintenance scheduling. Comput. Ind. Eng. 40, 149$160(2001)$

11. Kahraman, C., Beskese, A., Ruan, D.: Measuring flexibility of computer integrated manufacturing systems using fuzzy cash flow analysis. Inf. Sci. 168, 77-94 (2004)

12. Karsak, E.E., Tolga, E.: Fuzzy multi-criteria decision-making procedure for evaluating advanced manufacturing system investments. Int. J. Prod. Econ. 69, 49-64 (2001)

13. Kumar, V., Chaturvedi, S.K.: Prioritization of maintenance tasks on industrial equipment for reliability. Int. J. Qual. Reliab. Manag. 28(1), 109-126 (2011)

14. Önüt, S., Soner, S.: Trans-shipment site selection using the AHP and TOPSIS approaches under fuzzy environment. Waste Manag. (2007). doi:10.1016/j.wasman.2007.05.019

15. Quan, G., Greenwood, G.W., Liu, D., Hu, S.: Searching for multiobjective preventive maintenance schedules: combining preferences with evolutionary algorithms. Eur. J. Oper. Res. 177, 19691984 (2006)

16. Raj, P.A., Kumar, D.N.: Ranking alternatives with fuzzy weights using maximizing set and minimizing set. Fuzzy Sets Syst. 105, 365-375 (1999)

17. Samrout, M., Yalaoui, F., Chatelet, E., Chebbo, N.: New methods to minimize the preventive maintenance cost of series-parallel systems using ant colony optimization. Reliab. Eng. Syst. Saf. 89, 346-354 (2005)
18. Sohrabi, B., Mohammadi, K., Khanlari, A.: Prioritizing equipments for preventive maintenance (PM) activities using fuzzy rules. Comput. Ind. Eng. 54, 169-184 (2008)

19. Sortrakul, N., Nachtmann, H.L., Cassady, C.R.: Genetic algorithms for integrated preventive maintenance planning and production scheduling for a single machine. Comput. Ind. 56, 161-168 (2005)

20. Tsang, A.H.C.: Strategic dimensions of maintenance management. J. Qual. Maint. Eng. 8(1), 7-39 (2002)

21. Wang, T.C., Chang, T.H.: Application of TOPSIS in evaluating initial training aircraft under a fuzzy environment. Expert Syst. Appl. 33, 870-880 (2007)

22. Weinstein, L., Chung, C.H.: Integrating maintenance and production decisions in hierarchical production planning environment. Comput. Oper. Res. 26, 1059-1074 (1999)

23. Xu, Z.S., Chen, J.: An interactive method for fuzzy multiple attribute group decision making. Inf. Sci. 177, 248-263 (2007)

24. Zadeh, L.A.: The concept of a linguistic variable and its application to approximate reasoning. Inf. Sci. 8, 199-249(I), 301-357(II) (1975)

25. Zimmerman, H.J.: Fuzzy Sets Theory and Its Applications. Kluwer, Boston (1996) 